\title{
Journal of Health Sciences
}

\section{Evaluation of factors that affect skin to subarachnoid space distance}

\author{
Mehmet Sargin*, Bülent Hanedan², Eyüp Aydoğan³, Hatice Toprak³, Fatma Akin³, Sadık Özmen ${ }^{4}$ \\ ${ }^{1}$ Department of Anesthesiology and Reanimation, Isparta City Hospital, Isparta, Turkey, ${ }^{2}$ ADepartment of Anesthesiology and \\ Reanimation, Ordu Training and Research Hospital, Ordu, Turkey, ${ }^{3}$ Department of Anesthesiology and Reanimation, Konya Training \\ and Research Hospital, Konya, Turkey, ${ }^{4}$ Department of Anesthesiology and Reanimation, Antalya Training and Research Hospital, \\ Antalya, Turkey
}

\begin{abstract}
Introduction: Lumbar puncture is a procedure frequently used in anesthetic practice. For the success of the procedure, prediction of skin to subarachnoid space distance (SSD) is valuable. In this study, we aimed to evaluate the relationship between SSD with age and body mass index (BMI).

Methods: Two hundred and fifty patients, ASA physical status I, II, and III scheduled to undergo elective surgery under spinal anesthesia, were studied. Spinal anesthesia was induced in the sitting position at the L3-4 vertebral level using a midline approach. Furthermore, the level of L3-L4 was identified by palpation, using Tuffier's line as a guide. Following an intrathecal injection, the spinal needle was grasped between the thumb and the index finger during its removal from the patient's back. From the grasping point, SSD was measured using rulers.
\end{abstract}

Results: Mean values of SSD at the L3-4 interspace were $55.43 \pm 6.47 \mathrm{~mm}$ (range 35-74). Statistically significant correlations were observed between SSD with BMI and body weight $(\rho=0.650, P<0.001$ and $\rho=0.651, P<0.001$, respectively). Statistically significant correlation was not found between SSD with age, gender and body height ( $\rho=0.120, P=0.058 ; \rho=-0.047, P=0.4568$ and $\rho=0.089, P=0.159$, respectively).

Conclusions: SSD is affected by BMI and body weight but not by age, gender and body height.

Keywords: Spinal anesthesia; skin to subarachnoid space distance; body mass index; lumbar puncture

\section{INTRODUCTION}

Lumbar puncture is a commonly used method for the application of spinal anesthesia in anesthetic

\footnotetext{
*Corresponding author: Mehmet Sargin, Department of Anesthesiology and Reanimation, Isparta State Hospital, Isparta, Turkey.

Phone +905322662766

E-mail: mehmet21sargin@yahoo.com
}

Submitted: 12 February 2017/Accepted: 04 April 2017

DOI: https://doi.org/10.17532/jhsci.2017.425 practice. It is very important that the spinal needle is placed correctly during this procedure. The procedure is a difficult medical technique since it depends on the practitioner's skill, the patient's anatomy and comfort (1). Although, anatomy knowledge and technical skills are important, presumed prearrangement of the skin to subarachnoid space distance (SSD) may lead to the correct placement of the spinal needle. Anatomy knowledge and technical skills allow a less traumatic and less repetitive number rises in spinal anesthesia results (2). Failed spinal 
anesthesia attempts can seriously affect patient's comfort.

In different studies, SSD was evaluated and formulated in different patient populations (3-6). However, studies in which the relationship between SSD and age and body mass index (BMI) analyzed in the literature are limited. Therefore, we aimed to evaluate the relationship between and BMI in this study.

\section{METHODS}

\section{Patients}

Institutional Ethics Committee's approval and written consent from the patients were obtained for the study. Two hundred and fifty patients, over the age of 18, ASA physical status I, II, and III scheduled to undergo elective surgery under spinal anesthesia, were studied.

The exclusion criteria were known contraindication to neuraxial anesthesia, or allergy to bupivacaine, and preoperative presence of any other abdominal mass or ascites.

Patient characteristics including gender, age, body weight, body height, and BMI were recorded upon arrival to the operating theater.

All patients were expected to fast 6-8 hours before surgery and they had received premedication as per our hospital protocol. Routine monitors, consisting of a pulse oximeter, 3-lead ECG and a non-invasive blood pressure cuff, were applied. Following prehydration with Ringer's lactate solution $500 \mathrm{~mL}$, spinal anesthesia was induced with hyperbaric bupivacaine $10-12.5 \mathrm{mg}$ via a $25 \mathrm{G}$ Quincke-point spinal needle in the sitting position at the L3-4 vertebral level. An anesthesiologist with more than 5 years of experience (Hanedan B, Aydoğan E) performed the induction using the midline approach, as well as identified the possible place of L3-L4 by palpation, using Tuffier's line as a guide.

The spinal needle was inserted perpendicular to the skin and advanced until the loss of resistance was felt and confirmed by the first appearance of the free flow of cerebrospinal fluid. Following an intrathecal injection, the spinal needle was grasped between the thumb and the index finger during its removal from the patient's back. From the grasping point, the SSD was measured using rulers. Patients in whom the needle was retracted due to the patient's discomfort or the contact with bony structures, the change in needle angle, as well as those patients with bloody cerebrospinal fluid were excluded from the study.

\section{Statistical analyses}

Statistical analyses were performed with Statistical Package for Social Sciences (SPSS) 15.0 software (SPSS Institute, Chicago, IL, USA). Data were presented as mean \pm SD (normally distributed data), median (range) (skewed data) or number (\%). The Spearman correlation coefficient was also measured. A P-value less than 0.05 was considered statistically significant.

\section{RESULTS}

A total of 250 patients were enrolled in the present study and the patient demographic data are summarized in Table 1. Mean values of SSD at the L3-4 interspace were $55.43 \pm 6.47 \mathrm{~mm}$ (range 35-74).

Statistically significant correlations were observed between SSD with BMI and body weight $(\rho=0.650$, $\mathrm{P}<0.001$ and $\rho=0.651, \mathrm{P}<0.001$, respectively). Figures 1 and 2 show the correlation between SSD with BMI and body weight, respectively.

Lastly, no statistically significant correlation was found between SSD with age, gender, and body height $(\rho=0.120, P=0.058 ; \rho=-0.047, P=0.4568$ and $\rho=0.089, \mathrm{P}=0.159$, respectively).

\section{DISCUSSION}

In the present study, the mean value for SSD at the L3-4 interspace was $55.43 \pm 6.47 \mathrm{~mm}$. Statistically significant correlations were observed between SSD with BMI and body weight, but no statistically

TABLE 1. Patients' characteristics

\begin{tabular}{lc}
\hline Age, year & $51(18-86)$ \\
Gender, M/F & $176 / 74(70.4 / 29.6)$ \\
Body weight, $\mathrm{kg}$ & $74(50-120)$ \\
Body height, $\mathrm{cm}$ & $168(150-190)$ \\
Body mass index, $\mathrm{kg} / \mathrm{m}^{2}$ & $25.74(18.20-37.72)$ \\
Skin to subarachnoid distance, $\mathrm{mm}$ & $55.43(6.74)$ \\
\hline
\end{tabular}

Data presented as mean $\pm S D$ (normally distributed data), median (range) (skewed data) or number (\%) 


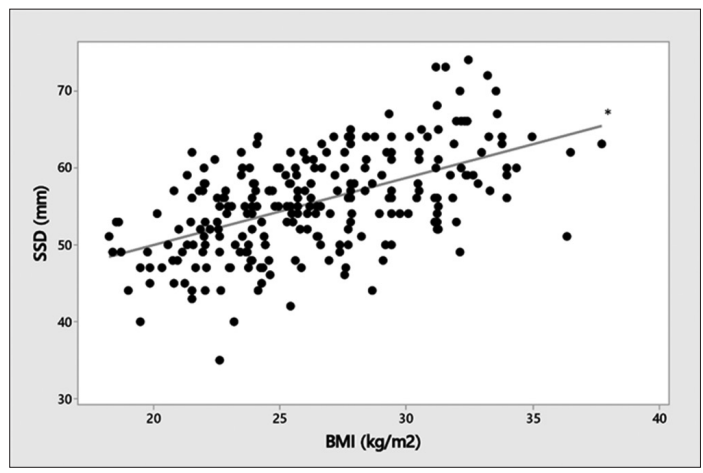

FIGURE 1. Correlation between the skin to subarachnoid distance (SSD) and body mass index (BMI), ( $\left.{ }^{*} \rho=0.650, P<0.001\right)$.

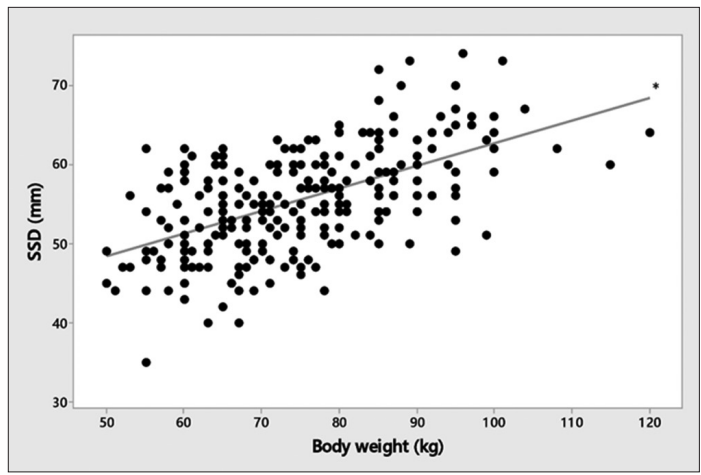

FIGURE 2. Correlation between the skin to subarachnoid distance (SSD) and body weight of the patients, $\left({ }^{*} \rho=0.651, P<0.001\right)$.

significant correlation was found between SSD with age, gender, and body height.

SSD has been investigated previously in several studies. SSD values vary in different studies. In the present study, SSD value was $55.43 \pm 6.47 \mathrm{~mm}$, while in the study performed by Basgül et al. (7), close values $(54.0 \pm 6.6 \mathrm{~mm})$ were reported. Furthermore, two different studies conducted in the Indian pop-

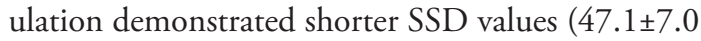
and $43.7 \pm 3.1)(5,8)$. In our opinion, the reason for the differences in the SSD values in the stated studies is due to the anthropometric differences between the study groups.

The previous studies have investigated the effects of different factors, such as age and body weight, on SSD values, similarly to the present study. In a study performed by Vassiliadis et al., in patients undergoing urological surgery, SSD showed a positive correlation with age, but reported no correlation between body weight, height, and BMI (9). Previously published studies conducted in parturients scheduled for caesarean section showed that there was a significant correlation between SSD with BMI and body weight $(6,10)$, similarly to the results obtained in the respective study.

The use of ultrasound has recently become increasingly prevalent in the practice of anesthesia, having positive results in neuraxial blocks. It has been reported that it is possible to accurately estimate the depth of intrathecal space using ultrasound, and well as to facilitate neuraxial blockade with spinal ultrasound (11). In addition to ultrasound studies, magnetic resonance imaging (MRI) studies for SSD detection are also available (12).

Our study has had limitations. The sample size was not calculated, therefore representing the major limitation to the study. Parturients were not included in this study. In addition, the angle of the spinal needle insertion was not measured. Regulation of the angle of the spinal needle insertion was left to the anesthetist who performed lumbar puncture and planned to penetrate the skin as straight as possible.

\section{CONCLUSION}

Our results indicate that SSD is affected by BMI and body weight. A study with a larger sample size is required to convincingly demonstrate whether SSD is affected by age, gender, and height.

\section{CONFLICT OF INTERESTS}

Authors declare no conflict of intetests.

\section{REFERENCES}

1. Howard SC, Gajjar AJ, Cheng C, Kritchevsky SB, Somes GW, Harrison PL, et al. Risk factors for traumatic and bloody lumbar puncture in children with acute lymphoblastic leukemia. JAMA 2002;288:2001-7.

https://doi.org/10.1001/jama.288.16.2001.

2. Watts RW. The influence of obesity on the relationship between body mass index and the distance to the epidural space from the skin. Anaesth Intensive Care 1993;21:309-10.

3. Taman HI, Farid AM, Abdelghaffar WM. Measuring skin to subarachnoid space depth in Egyptian population: A prospective cohort study. Anesth Essays Res 2016;10:468-72.

\section{https://doi.org/10.4103/0259-1162.179312.}

4. Basaran B, Basaran A, Kozanhan B, Ozmen S, Basaran M. The effect of preeclampsia on the skin to subarachnoid distance in spinal anesthesia. J Anesth. 2015;29:360-6.

https://doi.org/10.1007/s00540-014-1941-4. 
5. Prakash S, Mullick P, Chopra P, Kumar S, Singh R, Gogia AR. A prospective observational study of skin to subarachnoid space depth in the Indian population. Indian J Anaesth 2014;58:165-70.

https://doi.org/10.4103/0019-5049.130819.

6. Bassiakou E, Valsamidis D, Loukeri A, Karathanos A. The distance from the skin to the epidural and subarachnoid spaces in parturients scheduled for caesarean section. Minerva Anestesiol. 2011;77:154-9.

7. Basgul A, Cicek M, Hanci A, Korkmaz F, Dobrucali H, Koc E. A clinical prediction of skin to subarachnoid space distance in the urologic surgery patients: 189. Reg Anesth Pain Med 2005;30:48.

https://doi.org/10.1016/j.rapm.2005.07.112.

8. Hazarika R, Choudhury D, Nath S, Parua S. Estimation of Skin to Subarachnoid Space Depth: An Observational Study. J Clin Diagn Res. 2016;10:UC06-UC09.

https://doi.org/10.7860/jcdr/2016/21679.8755.

9. Vassiliadis M, Konstantinidou N, Anisoglou S, Papastefanou K.
Demographics and distance from skin to dura matter does it matter?: 17. Reg Anesth Pain Med. 2005;30 (Suppl 1):7.

https://doi.org/10.1016/j.rapm.2005.07.011.

10. Stamatakis E, Moka E, Siafaka I, Argyra E, Vadalouca A. Prediction of the distance from the skin to the lumbar epidural space in the Greek population, using mathematical models. Pain Pract 2005;5:125-34.

https://doi.org/10.1111/j.1533-2500.2005.05209.x.

11. Gnaho A, Nguyen V, Villevielle T, Frota M, Marret E, Gentili ME. Assessing the depth of the subarachnoid space by ultrasound. Rev Bras Anestesiol 2012;62:520-30.

https://doi.org/10.1016/S0034-7094(12)70150-2.

12. Franklin $A D$, Lorinc $A N$, Shotwell MS, Greene EB, Wushensky CA. Evaluation of the skin to epidural and subarachnoid space distance in young children using magnetic resonance imaging. Reg Anesth Pain Med. 2015;40:245-8.

https://doi.org/10.1097/AAP.0000000000000234. 